\title{
An Analysis of Population Return from the Perspective of Rural
}

\section{Urbanization}

\author{
Zhenpeng Duan ${ }^{1 *} \&$ Xinxin $\mathrm{Xu}^{1}$ \\ ${ }^{1}$ Faculty of Law and Politics, Zhejiang Agriculture and Forestry University, Lin'an 311300, Zhe Jiang, \\ China \\ * Zhenpeng Duan, E-mail: 1306160554@qq.com
}

Received: July 28, 2017

Accepted: August 10, 2017 Online Published: August 11, 2017

doi:10.22158/se.v2n3p309

URL: http://dx.doi.org/10.22158/se.v2n3p309

\begin{abstract}
Coming up with the idea of new type of urbanization drives great changes of rural area. However, there hasn't been high quality of rural urbanization compared with cities, which is becoming a weakness during the construction of urbanization. Therefore, it is very urgent to accelerate the construction of rural urbanization. Meanwhile, how to promote the development of rural area turns into a significant research field. Thus, as the main body of rural practical activities, human being becomes the developmental point of rural urbanization. The author puts forward the practical and theoretical policies via analyzing the influence factors "Push \& Pull" about the reflux of rural population to promote the development of rural area and achieve the goal of rural urbanization, with supplementing the rational escalation of "Boosting" in cities and increasing the "Homesickness" of outflowing peasants.
\end{abstract}

\section{Keywords}

rural area, urbanization, structure of population, reflux of rural population

\section{Introduction}

The previous vice president of World Bank, chief economist and Nobel Prize Winner, Joseph Stiglitz, put forward that there are two things that can affect and improve the world: one is the development of high-tech industry in USA and the other is the development process of China's urbanization (Zhang, 2013). In recent years, China promotes the new urbanization in order to improve it into a higher level and quality. However, rural areas are much less developed than cities because of the big gap between rural and urban areas and prominent urban-rural dual structure, which are all disadvantages that hinder the development process of urbanization. So it is necessary to change the backwardness of rural economy so as to speed up the development of urban-rural integration and facilitate the construction of new urbanization. Some scholars hold the view that it is the main problem that the development of rural 
areas lags behind the overall China's development (Li, 2014). Therefore, how to stimulate the development in rural area becomes a focus within governmental and academic circles. Throughout the current domestic study, the development of rural areas is based on the well urban-rural linkage, supported by government policy and structural reform, to improve the development of urban and rural integration, e.g., duralistic economic structure theory. Concluded the previous studies and based on the research on rural social activities, the paper is trying to discuss about the developmental path and method of urbanization from the perspective of peasants.

\section{Statement of Problem}

The construction of China's urbanization started relatively late in a slow way. However, with the implementation of the new idea of urbanization, the construction of urbanization has been through a incredible development. According to the national economy and society developed statistical bulletin in 2016 released by the NSBC (China's National Bereau of Statistics), there are more than 792 million inhabitants living in urban area which accounts for $57.35 \%$ of total population, ending the age of majority rural population. Government and academic research field are endeavoring to solve the problem of development of rural area because it is still relatively weaker during the urbanization, which makes positive effects for it (NSBC, 2017). However, there are still other problems to be solved, such as the big gap between rural and urban areas and the urban dual structure. Upon these researches and ideas, there is one very important factor being neglected that is hunman being. It plays a key role as the main body of rural urbanization. Karl Marx also believes that the people are the subject of practice, the creator of social material wealth and spiritual wealth. Although it is hilarious to use "386199 (Note 1) Troops" to decribe rural demographic structure, it still profoundly reveals the rural left-behind population structure. With the further development of China's market economy, the urban economy has been developed by leaps and bounds, the demand for labor force has been increasing, and the rural labor force has been attracted. At the same time, the " 38 " detachment, which is the "housekeeper" of the labor life and daily diet, followed the outflow, resulting in the structure like "6199" of rural left-behind population. All of the strategies would be be an armchair strategist without a subject to practice no matter there are good government policy, agracultural technology or scientific and rational rural planning system entering into rural area. Therefore, it is significant to guarantee that not only rural surplus labor force will stay in rural area, but also to promote the outflow of rural population will get back. Zeng also believes that the backflow of population will bring back new development opportunities and make the gap between urban and rural development gradually reduced (Zeng, Zhong, \& Wang, 2014).

Based on the theoretical and practical analysis, this paper puts forward the key hypothesis of rural urbanization that is human being. It plays an important role during the construction of rural urbanization, which is to make a large number of outflow population back, to change the rural population structure, and also not promote both the "38" group and the "54 (Note 2)" group return. From the perspective of "Want to go back home, Can go back home, Can stay in rural area", the paper explores new paths and ideas to 
promote the reflux of rural population and let the positive factors of rural urbanization take root in the countryside and bear fruit in order to better promote the rural urbanization.

\section{The Potential Influence Factors of Population Backflow}

It is pluralistic of the resistence and motivation for the backflow of China's mobile population and even it is more complicated. Concentrated on the a variety of related rights and interests generated by the outflow and inflow population, the relevant groups form a distinct interest groups consciously or unconsciously, and from their own specific point of view, to a certain extent, it promotes the return of the floating population and hinders its returnin the maintenance of their own interests. According to the characteristicsof the main body of the role, it can be summarized into two categories, one is the three groups of stakeholders including head of the executive, urban residents and villagers, the other is the different social space between rural and urban areas. Both of them have an impact on the return of floating population from different perspectives and different degree, meanwhile, the cross and collision of their influence forms an unexpected cooperation which promotes and hinders the smooth return of the floating population.

3.1 The Head of Executive Mentioned before in This Paper Includes the Heads of Government at All Level, Representated by Mayor in Both Inflow and Outflow Region

To a certain extent, it plays a dual role in the issue of floating population's reture. The first role is to cooperate and support the floating population backflow via "voting with their feet", while the other effect is resistance which magnifies the actual effect of resistance and obstacles infinitely by choosing a proper and legitimacypolicy. Therefore, the head of executive would be a difficult obstacle to overcome if the floating people are returned successfully and achieve a satisfied result.

\subsection{The Urban Resident Refers to the Inhabitant Who Live in Metropolis and Megalopolis}

Based on the consideration of self-interest and the value of foreign people, the urban resident would be a supporter or resistance for the the return of the rural populationin the maintenance of their own interests that are not damaged. If their self-interests are damaged, it would promote the return of rural population, while, if the foreign migrant workers can provide irreplaceable life services that are strongly retained, it could hinder the backflow of rural population. Through the investigation of the urban residents in Hangzhou, the immigrate population share the so-called "vested interests" with local resident. They are not willing to accept the migrant workers to stay in their city for a long time because of the deep-rooted label of migrant workers. On the contrary, the silence and deserted in Hangzhou city awake the urban resident to accept the migrant workers and hope they can stay and still provide basic living services when spring festival is coming and the rural population turn back. Therefore, a lot of urban residents who have clear attitude and may be cause the outbreak of mass incidents become a major influencing factorin the process of the rural population's return. 
3.3 The Rural Population Refers to the Indigenous People That Are Rural Residents and Live in Rural Areas for a Long Time

This paper takes E'long village as an example. Through visting the village, there are many elder people who are left in the village and it lacks of labor, abandons the benefits of agriculture, which results in the low level of social and economic development. From this level, the rural people support the return of rural population and hope it reinvigorate for the rural areas. At the same time, this village has limited land and farmers can only engage in simple agricultural activities so leads in the low economic benefits. While, the vested interests of land caused by outflow of population force the rural people vote for the opposite of rural population's backflow by "voting with their feet", which becoms the obstacle for rural population to return.

\subsection{In the Process of Urbanization, Urban Society Plays the Role of Pulling out the Rural Labor Force}

While the rural is the role of promoting the outflow of rural labor, which is the traditional "push and pull". But not everlasting, nowadays the city society is more to play the role in supporting the rural population back, and the rural area is the role of pulling backthe rural population. Urban and rural areas in the changing role with each other, become the responder in the return of the rural population, creating a good atmosphere of "Want to go back home, Can go back home, Can stay in rural area", providing more opportunities and possibilities for the return of rural population.

\section{The Feasible Recommendation on the Backflow of Rural Population}

As mentioned above, there exists impetus and resistance simultaneously for the return of population in practice, and even the same factor with the push and pull two kinds of effect. As Doug (2012) mentioned about the Shenzhen officialsin a book, on the one hand, they enjoy the services provided by, on the other hand, they want all of migrant workers back to the original village after consuming their valuable youth in the city. Therefore, formulating a feasible path to reform the structure of rural population is the key to promote the development of rural urbanization.

\section{1 "Practical Work" of Equal Rights and Interests of Rural Residents}

The "practical work" refers to adjust the basic way of rural population reform and change the "land rights of rural household registration" into "increasing the quality of rural residents". To put the equalization of social welfare and public services into the rural areas can make the villagers living in rural areas enjoy the same social benefits with urban residents, which gradually equalize the value of urban and rural residents and narrow down the hierarchical inequality. So it will achieve the welfare equality of rural social welfare system geographically based on keeping the vested interests of original rural population. The focus of this reform is to empower to the rural population and its essence is to improve the ability of rural areas to promote the outflow of population return, which is to realize "Want to go back, Can go back, Can stay in rural area" of outflow population. 


\subsection{Giving the Necessary Production Elements of the Return Population via "Theoretical Framework"}

The "theoretical framework" refers to reform the profitable household registration system and get rid of the dominant and implicit benefits of part of the population in the rural household registration, which is the weakness of household registration system. This is a radicalreform of dual-household registration system, and it can only be taken from point to surface in a gradual way of promotion so as not to cause rebels of all the vested interests groups or affect the smooth progress of the rural population structure and healthy operation. Through the exclusion method, the specific targets are locked to be excluded in order to maintain its vested interests in exchange for the return of population work smoothly. Meanwhile, there should not be a large amout of groups that are excluded and should not last in a long time. Or it will affect the stability of rural society, even some mass incidents. The feasible way is to determine an age line by administration. Those people who are above the age line and unbale to engage in agricultural production activities will be abolished its land rights but is equally exchanged by otherinterests. Then, this part of the land rights and interests will be transferred to the young labor force so that the floating population would realize that the rural areas have large demand for them and give priority to the production factors, which ultimately achieve the return of floating populationto "Can stay in rural area".

\subsection{To Expand the "Pushing Force" of City Rationally}

It is necessary to promote the intensive management model, get rid of the drawbacks of family management and social pressure, regulate the operation of the market mechanism, and to lead the enterprises that are on the edge of collapse and idle to reorganize rationally. So it can both retain the original market vitality and gain back the remaining labor force, resulting in the invisible "Pulling Force" to promote the return of the floating population. In addition, the household registration system should be further regulated and restrictions are put on those who has no substantive effort on the development of city based on setting the rational conditions of settling down in city, which increases the pressure of life and competition for the "special groups" that move to city blindly so that they form the thinking of "want to go back" consciously. Based on a rational condition hypothesis, it can effectively promote the return of the floating population, change the original rural population structure, improve the development of rural industries, and finally it will achieve "local urbanization" model.

\subsection{To Increase the "Homesickness" of Floating Population}

There are many original characteristics of rural culture to be explored, such as in lunar 15th of January, the whole family holds some activities to worship the God. In the meantime, based on maintaining the original image of village, to strengthen the infrustructure construction of village will evoke the "homesickness" of floating population. With the simulation of homesickness, the floating population will form the idea of "Want to go back", which can turn the floating population back, change the structure of rural population and promote the urbanization of E'long village. 


\subsection{To Improve the Quality of Rural Development}

In order to turn the floating population "Can go back", the rural areas should improve their self-development level and the acceptance rate of population. Even if it involves a wide range of factors, this paper is still trying to give some advice from the current condition of E'long village. Firstly, E'long village should continuously promote the construction of new village, increase its substantive quality and pay attention to the construction of village atmosphere and image and the self-management of villagers so that so that the villagers realize the village's civilization and harmony, and the well rural governance of "two committees" (village party branch and village committee).

The second one is to strive to develop high value-added rural industries. In addition, it is important to develop and improve the rural industrial development system, implement the state and the government's good policy and do not be falsified. The fourth one is to introduce green ecological development enterprises. Last but not least, a good and livable ecological environment should be created. These aspects of the efforts mentioned above will make the floating population of E'long village experience the good condition of the current development which provides basic infrastructure for them to "Can go back home".

\section{Reference}

Doug, S. (2012). Arrive City: The Last Human Migration with Our Future (X. H. Cheng, Trans.). Shanghai Translation Publishing House: 57.

Li, C. Y. (2014). Reform and strategy: Research on Rural Development under the Goal of "New Four Modernization" (Industrialization, Informatization, Urbanization, Agricultural modernization) in China, 30(252), 64-68.

National Economy and Society Developed Statistics. (2013). [EB/OL] China's National Bereau of $\begin{array}{lllll}\text { Statistics. } & \text { Retrieved } & 28 & \text { June, } & \end{array}$ http://www.stats.gov.cn/tjsj/zxfb/201702/t20170228_1467424.html

Zeng, W. X., Zhong, L., \& Wang, Y. S. (2014). On the Phenomenon of Reflux of Migrant Workers in Minority Nationalities-A Case Study of Hezhou City, Guangxi Zhuang Autonomous Region. Ability and Wisdom, 21, 339.

Zhang, X. (2013). The Important Task of the New Urbanization Is to Reshape the Social Structure[EB/OL]. In Chinese Communist Party News. Retrieved 18 June, 2013, from http://theory.people.com.cn/BIG5/n/2013/0618/c40531-21884727.html

\section{Notes}

Note 1.38 is the women; 61 is the children; 99 is the elder.

Note 2. "54" is the young man. 